\title{
PENGARUH KARAKTERISTIK BIOGRAFI TERHADAP CAKUPAN UKGS III OLEH PERAWAT GIGI DI KABUPATEN SEMARANG
}

\author{
Bambang Sutomo$^{1}$, Prasko ${ }^{2}$, Bedjo Santoso ${ }^{3}$
}

\begin{abstract}
In order to realize the development of health, one of which strived through the improvement of health care facilities. Health care facilities that are directly related to the community health center. Of its services by the health center, including prevention services via UKGS. UKGS coverage is still low, with the average number of new coaching first time visit to the elementary school in one year. This situation is still below the target of 2 times per year. Coverage SD UKGS fostered selective (stage III) reached $19.7 \%$, still below the target of $30 \%$ of the elementary schools should be doing UKGS selective (stage III). The purpose of the study to know the effect of the characteristics of a biography of UKGS III coverage by the dental nurse in Semarang district.

Research carried out by the non-experimental design, the category of the type of quantitative research is descriptive and explanatory study. Subjects were the entire dental nurses working in health centers in Semarang district as many as 35 people. Data analysis will be performed using univariate, bivariate and multivariate analyzes. Bivariate analysis done by correlation test Chi Square with a 95\% confidence level $(\alpha=0.05)$. Ha accepted if the $p$ value $<0.05$. Test the effect by using multiple logistic regression multivariate analysis with $\alpha=0.05$.

The results of research on the scope UKGS III dental nurse in coaching UKBM, UKGS coverage either category III (51.4\%), older age group of 19 people (54.3\%), educational background dental nurse was found with SPRG categories $(26,7 \%)$. state of the working period at most dental nurse working group long term (14-28 years) of $54.3 \%$. Results of correlation tests performed with Chi Square there is one variable that is related: education $p$ value $=0.005$, and there are two variables that showed no association namely: age variable $p$ value $=0.060$. The test results showed the effect was no significant effect of the level of education of respondents to the coverage UKGS III in Semarang district by using multivariate logistic regression analysis obtained $p$ value with $\mathrm{OR}=0.017(\operatorname{Exp} B)=15.11$. In addition to the OR obtained $(\operatorname{Exp} B)=15.11$ can be interpreted that if there is a dental nurse who has a higher education tend to be achieved coverage UKGS III with both categories 15 times, rather than dental nurses in secondary education (SPRG). Advice to the Head of Puskesmas Semarang District Health Office to provide opportunities for dental nurses undertake further education. Dental nurse to increase the activity UKGS improve coverage and further improve the frequency of coaching.
\end{abstract}

Key words : biography characteristics, scope of Stage III UKGS

1,2,3) Dosen Jurusan Keperawatan Gigi Poltekkes Kemenkes Semarang

\section{PENDAHULUAN}

Keberhasilan pembangunan kesehatan dapat diwujudkan melalui berbagai cara, salah satunya di upayakan melalui peningkatan fasilitas pelayanan kesehatan. Salah satu unit fasilitas pelayanan kesehatan adalah Puskesmas. Sesuai semangat 5 reformasi dan era otonomi daerah manajemen Puskesmas tertuang dalam UU No. 22 dan 25 tahun 1999 tentang Desentralisasi dan Otonomi Daerah, yang kemudian diganti dengan Undang-Undang Nomor 32 Tahun 2004 tentang Pemerintahan Daerah. Dalam UndangUndang tersebut Puskesmas termasuk 
dalam kategori Unit Pelaksanan Teknis Daerah, dibawah Dinas Kesehatan Kabupaten/Kota. Adanya perubahan transisi sistem pemerintahan maka terdapat beberapa perbedaan Puskesmas Pra desentralisasi dan era desentralisasi. Batasan Puskesmas di era disentralisasi adalah unit pelaksana pembangunan kesehatan di wilayah kerjanya. Adapun fungsi puskesmas adalah :1). sebagai pusat penggerak pembangunan berwawasan kesehatan ; 2) pusat pemberdayaan masyarakat dan keluarga dalam pembangunan kesehatan ; 3) pusat pelayanan kesehatan tingkat pertama(Muninjaya, 2004).

$$
\text { Adanya laju perkembangan }
$$
pemerintahan, maka di era Kementerian Kesehatan Republik Indonesia yang dulunya Departemen Kesehatan RI, maka fungsi Puskesmas yang dahulunya ada 3, kemudian mengalami perubahan menjadi 4, yaitu : 1) pusat pembangunan kesehatan diwilayah kerjanya ; 2) pusat pemberdayaan masyarakat ; 3) pusat pelayanan kesehatan masyarakat primer ; 4) pelayanan kesehatan perorangan primer (Menkes RI, 2010).

Dalam menjalankan fungsinya, sesuai standar pelayanan kesehatan gigi di Puskesmas, maka jenis pelayanan kesehatan gigi dan mulut di Puskesmas Salah satu jenis pelayanan yang diberikan Puskesmas adalah pelayanan pencegahan. Pelayanan pencegahan ditujukan kepada 3 kelompok yaitu : komunitas, kelompok, dan perorangan. Pelayanan yang ditujukan kepada kelompok : promosi kesehatan gigi dan mulut melalui pendekatan komunikasi informasi dan edukasi kepada kelompok tertentu melalui program UKGS (Depkes RI,2009).

UKGS merupakan salah satu upaya dan wujud peranserta langsung masyarakat. Kewajiban peran serta masyarakat seperti terrsebut dalam Pasal 9 UU No. 36 Tahun 2009 Tentang kesehatan, pada ayat (1) berbunyi : Setiap orang berkewajiban ikut mewujudkan, mempertahankan, dan meningkatkan derajat kesehatan masyarakat yang setinggi-tingginya. Adanya kewajiban ini, menunjukan bahwa pembangunan kesehatan tidak hanya menjadi tanggung jawab pemerintah dan tenaga kesahatan saja, tetapi juga merupakan tangggung jawab bersama termasuk masyarakat. Dalam pelaksanaannya pemerintah mempunyai kewajiban menyelenggarakan dan membina penyelenggaraan upaya pelayanan kesehatan, hal ini sesui yang tercantum dalam Pasal 14 UU No. 36 Tahun 2009 Tentang Kesehatan, pada ayat (1) dijelakan bahwa : pemerintah bertanggung jawab merencanakan, mengatur, menyelenggarakan, membina, dan mengawasi penyelenggaraan upaya kesehatan yang merata dan terjangkau oleh masyarakat. Selanjutnya dalam Pasal 18 dijelaskan : Pemerintah bertanggung jawab memberdayakan dan mendorong peran aktif masyarakat dalam segala bentuk upaya kesehatan (Muninjaya, 2004) .

Sebagai bentuk realisasi pembinaan peran serta masyarakat, tenaga kesehatan salah satunya tenaga kesehatan gigi mempunyai tanggung jawab penuh dalam hal pembinaan adalah perawat gigi, hal ini sesuai dengan tugas pokok perawat gigi yaitu memberikan pelayanan asuhan kesehatan gigi dan mulut. Pelayanan asuhan kesehatan gigi dalah bentuk pelayanan kesehatan yang terencana, ditujukan kepada kelompok tertentu secara berkesinambungan dalam kurun waktu tertentu untuk mewujudkan derajad kesehatan yang optimal (Depkes RI, 2000).

Rendahnya cakupan pembinaan juga terjadi di Kabupaten Semarang, data kegiatan yang diperoleh dari Dinas Kesehatan kabupaten Semarang pada kurun waktu kegiatan Tahun 2009. Pelayanan di tingkat sekolah melalui program UKGS jumlah pembinaan rata-rata baru 1 kali per SD per tahun, keadaan ini masih dibawah target yaitu 2 kali per tahun. Cakupan SD yang dibina UKGS selektif (tahap III) baru $19, \%$, masih dibawah target sebesar $30 \%$ jumlah SD yang ada seharusnya melakukan UKGS selektif (tahap III)(Dinas Kesehatan Kabupaten Semarang, 2009). 
Hasil studi pendahuluan juga didapatkan sebagian besar responden dalam kondisi umur diatas 35 tahun. Peranan umur terhadap hasil sebuah pekerjaan akan sangat berkaitan. Menurut Robins, yang menyampaikan bahwa kinerja pekerja akan menurun seiring bertambahnya usia. Hal lain juga disampikan adanya beberapa alasan yang membuat produktivitas yang menurun, pada para pekerja tua dipandang kurang memiliki fleksibilitas dan sering menolak teknologi baru.

Selain itu dalam studi pendahuluan juga didapatkan data bahwa sebagian besar responden memiliki masa kerja yang lama. Menurut penelitian terdahulu, menyatakan bahwa pengalaman kerja memiliki pengaruh positif dan signifikan terhadap produktivitas kerja.

Berdasar keadaan tersebut, maka kami berkeinginan untuk mengetahui apakah ada pengaruh karakteristik biografi terhadap cakupan UKGS III oleh perawat gigi di Kabupaten Semarang.

\section{METODE PENELITIAN}

Penelitian dilakukan secara deskriptif kuantitatif dengan explanatory study. Peneliti berkeinginan untuk melihat pengaruh faktor biografi umur, pendidikan dan masa kerja terhadap cakupan UKGS tahap III oleh perawat gigi di Puskesmas Kabupaten Semarang. Pendekatan penelitian untuk pengambilan data dengan Cross-Sectional,

Subyek penelitian penelitian adalah seluruh perawat gigi yang bekerja di Puskesmas di Kabupaten Semarang sebanyak 35 orang.

Analisa data akan dilakukan secara univariat, bivariat dan multivariat. Analisis univariat akan dilakukan untuk mengetahui secara diskriptip distribusi masing-masing variabel. Analisis univariat akan dilakukan dengan menggunakan analisis deskriptip dengan menampilkan persentase guna untuk melihat secara diskripsi masingmasing variabel. Analisis bivariat akan dilakukan dengan korelasi bivariat dengan tujuan untuk mengetahui ada tidaknya hubungan antara masing-masing variabel. Untuk pelaksanaan analisis akan dilakukan dengan uji corelation study. Sesuai sifat data non parametrik maka uji korelasi dengan menggunakan uji korelasi Chi Square $(\times 2)$, dengan tingkat kepercayaan 95\% ( $\alpha=$ $0,05)$. Ha diterima apabila nilai $p$ value < 0,05 . Uji pengaruh dengan menggunakan análisis multivariat regresi logistic ganda dengan $\alpha=0,05$.

\section{HASIL DAN PEMBAHASAN}

Hasil penelitian mengenai Cakupan UKGS III perawat gigi dalam pembinaan UKBM, sudah dilakukan terhadap 35 responden perawat gigi yang bekerja di Puskesmas Kabupaten Semarang. Penelitian dilakukan dengan menggunakan instrument penelitian berupa kuesioner. Selengkapnya didapatkan beberapa hasil sebagai berikut :

\section{Keadaan Karakteristik Responden}

\section{Keadaan Umur}

Tabel 1. Distribusi keadaan umur perawat gigi di Kabupaten Semarang

\begin{tabular}{cccc}
\hline NO & KEADAAN UMUR & $\sum$ & \% \\
\hline 1 & Muda $(<35)$ & 16 & 45,7 \\
\hline 2 & Tua $(\geq 35)$ & 19 & 54,3 \\
\hline & Total & 35 & 100,0 \\
\hline
\end{tabular}

Persentase paling banyak adalah kelompok umur tua sebesar 19 orang (54,3\%), dibandingkan pada kelompok umur muda sebanyak 16 orang $(45,7 \%)$.

\section{Latar Belakang Pendidikan}

Tabel 2. Distribusi keadaan latar belakang pendidikan perawat gigi di Kabupaten Semarang

\begin{tabular}{clcc}
\hline NO & \multicolumn{1}{c}{ PENDIDIKAN } & $\sum$ & $\%$ \\
\hline 1 & $\begin{array}{l}\text { Tingkat pendidikan menengah } \\
\text { (SPRG) }\end{array}$ & 9 & 25.7 \\
\hline 2 & $\begin{array}{l}\text { Tingkat pendidikan tinggi } \\
\text { (D III dan D IV Keperawatan Gigi) }\end{array}$ & 26 & 74.3 \\
\hline & 35 & 100,0 \\
\hline
\end{tabular}


Pada Tabel 2, menunjukan bahwa keadaan pendidikan untuk kategori SPRG sebesar 9 orang (26,7\% persentasenya kecil, dibandingkan dengan tingkat pendidikan tinggi ( D III dan D IV Keperawatan Gigi sebesar 26 orang $(74,3 \%)$.

\section{Masa Kerja}

Tabel 3. Distribusi keadaan masa kerja perawat gigi di Kabupaten Semarang

\begin{tabular}{cccc}
\hline NO & KEADAAN MASA KERJA & $\sum$ & $\%$ \\
\hline 1 & Sebentar $(1-13$ tahun $)$ & 16 & 45,7 \\
\hline 2 & Lama $(14-28$ tahun $)$ & 19 & 54,3 \\
\hline \multicolumn{2}{c}{ Total } & 35 & 100,0 \\
\hline
\end{tabular}

Pada Tabel 3 menunjukan bahwa persentase paling besar adalah kelompok masa kerja sebentar (1 - 13 tahun) sebesar $45,7 \%$, dibandingkan pada kelompok masa kerja lama (14 - 28 tahun) sebesar 54,3\%.

\section{Cakupan UKGS III}

Tabel 4. Distribusi keadaan cakupan UKGS II di Kabupaten Semarang

\begin{tabular}{clcc}
\hline NO & KEADAAN CAKUPAN & $\sum$ & \% \\
\hline 1 & Kurang & 17 & 48,6 \\
\hline 2 & Baik & 18 & 51,4 \\
\hline \multicolumn{2}{c}{ Total } & 35 & 100,0 \\
\hline
\end{tabular}

Pada Tabel 4 menunjukan bahwa cakupan UKGS III dengan kategori kurang sebesar 17 orang $(48,6 \%)$, proporsinya lebih rendah dibandingkan cakupan UKGS III dengan kategori baik sebesar 18 orang $(51,4 \%)$.

\section{Hubungan Antara Keadaan Umur dengan Cakupan UKGS III}

Tabel 5. Distribusi silang umur dengan Cakupan UKGS III

\begin{tabular}{|c|c|c|c|c|c|c|c|}
\hline \multirow{2}{*}{ NO } & \multirow{2}{*}{$\begin{array}{l}\text { KATEGORI } \\
\text { UMUR }\end{array}$} & \multicolumn{4}{|c|}{ CAKUPAN UKGS II } & \multicolumn{2}{|c|}{ TOTAL } \\
\hline & & KURANG & $\%$ & BAIK & $\%$ & $\mathrm{n}$ & $\%$ \\
\hline 1 & $\begin{array}{l}\text { Muda } \\
\text { (22- } 34 \text { tahun) }\end{array}$ & 5 & 31,3 & 11 & 68,8 & 16 & 100 \\
\hline 2 & $\begin{array}{l}\text { Tua } \\
\text { (35- } 50 \text { tahun) }\end{array}$ & 12 & 63,2 & 7 & 36,8 & 19 & 100 \\
\hline
\end{tabular}

Pada responden dengan kelompok umur muda, menjadikan cakupan UKGS III dengan kategori kurang sebesar 5 orang $(31,3 \%)$ proporsinya lebih kecil jika dibandingkan dengan cakupan UKGS III dengan kategori baik sebesar 11 orang $(68,8 \%)$.

Sedangkan untuk kelompok umur tua, menjadikan cakupan UKGS III dengan kategori kurang sebesar 12 orang $(63,2 \%)$ proporsinya lebih besar jika dibandingkan dengan cakupan UKGS III dengan kategori baik sebesar 7 orang $(36,8 \%)$.

Setelah dilakukan uji korelasi dilakukan dengan Chi Square, dengan tingkat kepercayaan 95\% $(\alpha=0,05)$, diperoleh $p$.value $=0,060$, karena $p$ value $>a$ maka $\mathrm{H} 0$ diterima dan Ha ditolak, sehingga tidak ada hubungan antara umur dengan cakupan UKGS III di Kabupaten Semarang.

\section{Hubungan Tingkat Pendidikan dengan Cakupan UKGS III}

Tabel 6. Distribusi silang keadaan tingkat pendidikan dengan Cakupan UKGS II di Kab. Semarang

\begin{tabular}{ccccccccc}
\hline \multirow{2}{*}{ NO } & PENDIDIKAN & \multicolumn{3}{c}{ CAKUPAN UKGS III } & \multicolumn{3}{c}{ TOTAL } \\
\cline { 2 - 8 } & KURANG & $\%$ & BAIK & $\%$ & $\mathrm{n}$ & $\%$ \\
\hline 1 & $\begin{array}{l}\text { Tingkat pendidikan } \\
\text { menengah (SPRG) }\end{array}$ & 8 & 88,9 & 1 & 11,1 & 9 & 100 \\
\hline 2 & $\begin{array}{l}\text { Tingkat pendidikan } \\
\text { tinggi (D III dan D }\end{array}$ & & & & & & \\
& $\begin{array}{l}\text { IV } \\
\text { KEPERAWATAN } \\
\text { GIGI) }\end{array}$ \\
\hline p.value $=0,005$, Ho ditolak & & 34,6 & 17 & 65,4 & 26 & 100 \\
& & & & & & & \\
\hline
\end{tabular}

Pada responden dengan Tingkat pendidikan menengah (SPRG), menjadikan cakupan UKGS III dengan kategori kurang sebesar 8 orang $(88,9 \%)$ proporsinya lebih besar jika dibandingkan dengan cakupan UKGS III dengan kategori baik sebesar 1 orang $(11,1 \%)$.

Sedangkan untuk Tingkat pendidikan tinggi (D III dan D IV Keperawatan Gigi), menjadikan cakupan UKGS III dengan kategori kurang sebesar 9 orang $(88,9 \%)$ proporsinya lebih kecil jika dibandingkan 
dengan cakupan UKGS III dengan kategori baik sebesar 17 orang $(65,4 \%)$.

Setelah dilakukan uji korelasi dilakukan dengan Chi Square, dengan tingkat kepercayaan 95\% $(\alpha=0,05)$, diperoleh p.value $=0,005$, karena $p$ value $<\mathrm{a}$ maka H0 ditolak dan Ha diterima, sehingga ada hubungan yang bermakna antara tingkat pendidikan dengan cakupan UKGS III di Kabupaten Semarang.

\section{Hubungan Masa Kerja dengan Cakupan UKGS III}

Tabel 7. Distribusi silang keadaan masa kerja dengan Cakupan UKGS III

\begin{tabular}{lccccccc}
\hline \multirow{2}{*}{ NO } & KATEGORI & \multicolumn{3}{c}{ CAKUPAN UKGS III } & \multicolumn{3}{c}{ TOTAL } \\
\cline { 2 - 8 } & MASA KERJA & KURANG & $\%$ & BAIK & $\%$ & $\mathrm{n}$ & $\%$ \\
\hline 1 & Baru & 5 & 31,3 & 11 & 68,8 & 16 & 100 \\
\hline 2 & Lama & 12 & 63,2 & 7 & 36,8 & 19 & 100 \\
\hline p.value $=0,060$, H0 diterima & & & &
\end{tabular}

Pada responden dengan kelompok masa kerja baru, menjadikan cakupan UKGS III dengan kategori kurang sebesar 5 orang $(31,3 \%)$ proporsinya lebih besar jika dibandingkan dengan cakupan UKGS III dengan kategori baik sebesar 11 orang $(68,8 \%)$.

Sedangkan untuk kelompok masa kerja lama, menjadikan cakupan UKGS III dengan kategori kurang sebesar 12 orang $(63,2 \%)$ proporsinya lebih besar jika dibandingkan dengan cakupan UKGS III dengan kategori baik sebesar 7 orang $(36,8 \%)$.

Setelah dilakukan uji korelasi dilakukan dengan Chi Square, dengan tingkat kepercayaan 95\% $(\alpha=0,05)$, diperoleh p.value $=0,060$, karena $p$ value $>$ a maka $\mathrm{H} 0$ diterima dan Ha ditolak, sehingga tidak ada hubungan yang bermakna antara masa kerja dengan cakupan UKGS III di Kabupaten Semarang.
Tabel 8. Rekap uji bivariat variabel independent dengan variabel dependent Cakupan UKGS III oleh perawat gigi di Puskesmas Kabupaten Semarang

\begin{tabular}{|c|c|c|c|c|}
\hline No & $\begin{array}{c}\text { Variabel } \\
\text { independent }\end{array}$ & $\begin{array}{c}\text { Variabel } \\
\text { dependent }\end{array}$ & p. value & Keterangan \\
\hline 1 & Umur & \multirow{3}{*}{$\begin{array}{l}\text { Cakupan UKGS III } \\
\text { Perawat Gigi dalam } \\
\text { - kegiatan UKBM di } \\
\text { Kabupaten } \\
\text { Semarang }\end{array}$} & 0,060 & $\begin{array}{l}\text { Tidak ada } \\
\text { hubungan }\end{array}$ \\
\hline 2 & Masa kerja & & 0,005 & Ada hubungan \\
\hline 3 & Pendidikan & & 0,060 & $\begin{array}{l}\text { Tidak ada } \\
\text { hubungan }\end{array}$ \\
\hline
\end{tabular}

Tabel diatas memperlihatkan bahwa setelah dilakukan uji korelasi dengan Chi Square dengan dengan tingkat kepercayaan $95 \%(\alpha=0,05)$, maka didapatkan :

1. Terdapat 1 variabel independent yang berhubungan dengan variabel dependent, yaitu : Variabel pendidikan hasil uji statistik dengan Chi Square, dengan tingkat kepercayaan 95\% ( $\alpha=$ $0,05)$, diperoleh $p$.value $=0,005$, karena $p$ value < a, maka Ho ditolak dan $\mathrm{Ha}$ diterima sehingga ada hubungan yang bermakna antara pendidikan dengan cakupan UKGS III di Kabupaten Semarang.

2. Terdapat 2 variabel yang menunjukan tidak ada hubungan yaitu : variabel umur dengan p.value $=0,060$, masa kerja dengan p.value $=0,060$.

\section{Hasil Pengolahan Data dan Análisis Multivariat}

Tabel 9. Hasil uji statistik pengaruh faktor pendidikan dan upah/gaji terhadap variabel dependent Cakupan UKGS III di Puskesmas Kabupaten Semarang

\begin{tabular}{|c|c|c|c|c|c|c|}
\hline \multirow[b]{2}{*}{ No } & \multirow[b]{2}{*}{ Variabel } & \multirow[b]{2}{*}{$\begin{array}{c}\text { Nilai } \\
\text { (p.value) }\end{array}$} & \multirow[b]{2}{*}{ B } & \multirow{2}{*}{$\begin{array}{c}\text { OR/ } \\
\operatorname{Exp}(B)\end{array}$} & \multicolumn{2}{|c|}{$95.0 \%$} \\
\hline & & & & & $\begin{array}{c}\text { Batas } \\
\text { bawah }\end{array}$ & $\begin{array}{c}\text { Batas } \\
\text { atas }\end{array}$ \\
\hline 1 & Pendidikan & 0,017 & 2,75 & 15,11 & 1,624 & 140,580 \\
\hline 2 & Constant & 0,026 & $-4,795$ & 0,08 & & \\
\hline
\end{tabular}

Berdasarkan tabel diatas setelah dilakukan uji pengaruh dengan menggunakan análisis multivariat regresi logistic ganda dengan $a=0,05$, maka didapatkan p.value dari variabel pendidikan 
$=0,017$ dengan OR $(\operatorname{Exp} B)=15,11$. Berdasarkan hasil tersebut dengan p.value $=$ 0,017, karena p.value < a, maka dapat dinterprestasikan ada pengaruh yang signifikan dari tingkat pendidikan responden terhadap cakupan UKGS III di Kabupaten Semarang. Selain itu dengan didapatkan OR $(\operatorname{Exp} B)=15,11$ dapat diinterprestasikan bahwa jika ada perawat gigi yang mempunyai pendidikan tinggi cenderung untuk dapat tercapai cakupan UKGS III dengan kategori baik sebanyak 15 kali, daripada perawat gigi yang dalam pendidikan menengah (SPRG).

\section{Cakupan Pembinaan UKGS tahap III}

Hasil penelitian terhadap 35 orang responden yang tersebar di 19 kecamatan pada 26 Puskesmas didapatkan cakupan UKGS II sebagian besar dalam kategori baik sebesar 18 orang $(51,4 \%)$.

Pada UKGS tahap III, didapatkan hasil bahwa SD yang sudah dibina sesuai target (2 kali dalam satu tahun) yaitu sebanyak 343 SD $(66,1 \%)$, dan dibina 3 kali dalam setahun 42 SD (8,1\%), yang tidak pernah dilakukan pembinaan dalam 1 tahun sebanyak 18 SD (3,5\%), dan masih ditemukan frekuensi pembinaan yang dibawah target yaitu hanya dibina 1 kali dalam setahun sebanyak 116 SD (22,4\%).

Belum tercapainya pembinaan UKGS belum sesuai dengan teori yang diharapkan yaitu sebanyak $30 \%$ jumlah SD yang harus dibina UKGS tahap III.

Belum optimalnya pembinaan UKGS tahap III menunjukan bahwa fungsi Puskesmas belum berjalan sebagaimana mestinya, baik dalam hal sebagai pusat pembangunan kesehatan, sebagai pusat pemberdayaan maupun sebagai pelayanan kesehatan masyarakat primer. Hal ini sesuai teori yang menjelaskan bahwa fungsi Puskesmas yaitu : 1) pusat pembangunan kesehatan diwilayah kerjanya ; 2) pusat pemberdayaan masyarakat ; 3) pusat pelayanan kesehatan masyarakat primer ; 4) pelayanan kesehatan perorangan primer(Menkes RI, 2010).

Selain itu belum optimalnya pembinaan menunjukan belum berjalannya fungsi penyelenggaraan, pembinaan dan pengawasan penyelenggaraan upaya kesehatan yang seharunya dijalankan pemerintah, yang dalam hal ini Puskesmas, hal ini sebagaimana tersebut dalam Pasal 14 UU No. 36 Tahun 2009 Tentang Kesehatan, pada ayat (1) dijelakan bahwa : pemerintah bertanggung jawab merencanakan, mengatur, menyelenggarakan, membina, dan mengawasi penyelenggaraan upaya kesehatan yang merata dan terjangkau oleh masyarakat. Selanjutnya dalam Pasal 18 dijelaskan : Pemerintah bertanggung jawab memberdayakan dan mendorong peran aktif masyarakat dalam segala bentuk upaya kesehatan.

\section{Hubungan Umur Perawat Gigi dengan Cakupan UKGS III Perawat Gigi di Kabupaten Semarang}

Hasil penelitian menunjukan bahwa tidak ada hubungan antara umur dengan Cakupan UKGS II. Keadaan ini menunjukan bahwa adanya distribusi umur tua yang proporsinya lebih besar jika dibandingkan dengan proporsi umur muda, ternyata tidak berdampak pada perubahan kearah peningkatan cakupan. Idealnya dengan banyaknya kelompok usia tua seharusnya cakupannya menjadi lebih baik, karena dengan bertambahnya umur seseorang seharusnya kemmpuan daya berpikir dan kematangan psikologis seseorang akan bertambah.

Keadaan yang terjadi di Kabupaten Semarang, kemungkinan besar dengan bertambahnya umur, akan diikuti juga dengan menurunnya capain hasil sebuah pekerjaan. Hal ini sesuai dengan teori yang dikemukan oleh Robins, yang menyampaikan bahwa kinerja pekerja akan menurun seiring bertambahnya usia. Hal lain juga disampikan adanya beberapa alasan yang membuat cakupan yang menurun, pada para pekerja tua dipandang 
kurang memiliki fleksibilitas dan sering menolak teknologi baru.

\section{Hubungan Tingkat Pendidikan Perawat Gigi terhadap Cakupan UKGS III di Kabupaten Semarang}

Kategori tingkat pendidikan di Kabupaten Semarang sangat bervariasi, mulai dari SPRG, Diploma III kesehatan gigi, dan Diploma IV kesehatan gigi. Dalam pengelompokan tingkat pendidikan, diharapkan pendidikan minimal adalah Diploma III. Oleh karena itu dalam penelitian ini perawat gigi lulusan SPRG masuk dalam kategori pendidikan menengah, sedangkan lulusan D III dan D IV masuk dalam kategori pendidikan tinggi.

Hasil penelitian menunjukan ada hubungan antara tingkat pendidikan dengan cakupan UKGS III. Pada kategori tingkat pendidikan menengah (SPRG) cenderung kurang, sedangkan pada tingkat pendidikan tinggi (D III dan DIV) cenderung menjadikan cakupan baik. Hasil uji statistik menunjukan ada hubungan antara pendidikan dengan cakupan UKGS II.

Pada kelompok perawat gigi yang sudah mengikuti pendidikan berkelanjutan bisa sepenuhnya menghasilkan cakupan yang baik. Realitas ini menunjukan bahwa dengan pendidikan berkelanjutan yang dilakukan pada perawat gigi di Kabupaten Semarang bisa meningkatkan kemampuan intelektual seseorang dalam menjalankan berbagai aktifitas.

Hal ini sesuai dengan arti dari pendidikan menurut kamus, bahwa pendidikan diartikan sebagai proses dimana seseorang mengembangkan kemampuan, sikap dan bentuk-bentuk tingkah laku lainnya dalam masyarakat dimana dia hidup.

\section{Hubungan Masa Kerja Perawat Gigi terhadap Produktivitas Kerja Perawat Gigi di Kabupaten Semarang}

Hasil penelitian menunjukan bahwa tidak ada hubungan masa kerja dengan cakupan UKGS III. Hal ini menunjukan bahwa perjalanan waktu seseorang dalam menjalani pekerjaannya ternyata tidak memberikan masukan positip dalam kenaikan cakupan UKGS. Bisaanya seseorang yang sudah bekerja lama mempunyai banyak pengalaman dan strategi-strategi yang yang beraneka macam dalam mensiasati pekerjaannya. Apa yang terjadi di perawat gigi di Kabupaten Semarang tentunya tidaklah demikian, adanya penambahan masa kerja justru menurunkan cakupan.

Hal ini bertentangan dengan teori yang disampaikan oleh Gordon dan Fitzgibbons, bahwa ada hubungan antara senioritas dan produktivitas. Senioritas diartikan sebagai waktu pada suatu pekerjaan, maka kita dapat berkata bahwa adanya bukti baru yang menunjukan adanya hubungan positip antara senioritas dengan produktivitas pekerjaan. Masa jabatan jika diartikan sebagai pengalaman pekerjaan, tampaknya menjadi sebuah dasar perkiraan yang baik atas produktivitas karyawan.

\section{Pengaruh variabel pendidikan terhadap cakupan UKGS.}

Hasil penelitian dan uji statistik yang menunjukan adanya pengaruh antara tingkat pendidikan dengan cakupan UKGS. Hal ini juga bisa dilihat dari distribusi yang terjadi yang menunjukan bahwa kecenderungan kelompok pendidikan rendah yaitu SPRG menjadikan cakupan kurang, sedangkan pada pendidikan tinggi menjadikan cakupan baik.

Hasil penelitian menunjukan bahwa proses pengembangan lewat pendidikan lanjut dapat meningkatkan cakupan, maka proses perkembangan potensi peserta didik yang didapat disaat mengikuti pendidikan bisa terwujud. Hasil penelitian membuktikan bahwa tujuan seseorang mengikuti pendidikan bisa meningkankan potensi seseorang. Sebagaimana dijelaskan 
dalam Undang Undang RI. No. 20 Tahun 2003 Tentang Sistem Pendidikan Nasional, yang menjelaskan bahwa pendidikan bertujuan untuk meningkatkan berkembangnya potensi peserta didik agar menjadi manusia yang beriman dan bertakwa kepada Tuhan Yang Maha Esa, berakhlak mulia, sehat, berilmu, cakap, kreatif, mandiri, dan menjadi warga negara yang demokratis serta bertanggung jawab.

Faktor pendidikan merupakan faktor biografi responden, dengan pendidikan yang tinggi akan berpengaruh untuk lebih meningkatkan cakupan, karena dengan pendidikan tinggi menjadikan tambahan wawasan dan pengetahuan bagi seseorang.

Selain itu dengan mengikuti pendidikan bisa meningkatkan kemampuan perawat gigi bisa dalam meningkatkan cakupan pembinaan UKGS. Hal ini sesuai dengan batasan mengenai pendidikan seperti yang tersebut dalam UndangUndang No. 20 Tahun 2003 Tentang Sistem Pendidikan Nasional Pasal 1 ayat (1) menjelaskan pengertian pendidikan adalah usaha sadar dan terencana untuk mewujudkan suasana belajar dan proses pembelajaran agar peserta didik secara aktif mengembangkan potensi dirinya untuk memiliki kekuatan spiritual keagamaan, pengendalian diri, kepribadian, kecerdasan, akhlak mulia, serta keterampilan yang diperlukan dirinya, masyarakat, bangsa dan negara.

Adanya pengaruh dari variabel pendidikan terhadap cakupan, sesuai dengan hasil penelitian sebelumnya yang dilakukan oleh Pajar dengan sampel adalah perawat Rumah Sakit PKU Muhammadiyah Surakarta pada tahun 2008, yang menyatakan bahwa tingkat pendidikan, memiliki pengaruh positif dan signifikan terhadap produktivitas kerja perawat di RS. PKU Muhammadiyah Surakarta.

\section{KESIMPULAN}

a. Cakupan UKGS III perawat gigi di Kabupaten Semarang masuk dalam kategori baik sebesar 18 orang (51,4 \%).

b. Karakteristik responden untuk variabel umur yang paling banyak adalah kelompok umur tua (35-50 tahun) sebesar (54\%), tingkat pendidikan perawat gigi paling banyak adalah tingkat pendidikan tinggi (D III dan D IV Kesehatan Gigi) (74\%), dan masa kerja perawat gigi paling banyak adalah kategori lama (16 -28 tahun) sebesar (54\%).

c. Ada hubungan antara pendidikan dengan cakupan pembinaan UKGS tahap III oleh perawat gigi di Kabupaten Semarang, dengan $p$. value $=0,005$.

d. Ada pengaruh tingkat pendidikan terhadap cakupan pembinaan UKGS tahap III oleh perawat gigi di Kabupaten Semarang, dengan $p$. value $=0,017$, dan Ex (B) $=15,11$

\section{SARAN}

a. Kepada Kepala Puskesmas Dinas Kesehatan Kabupetan Semarang untuk lebih memberikan kesempatan pada perawat gigi untuk melakukan pendidikan lanjut, guna peningkatan pengetahuan, sikap dan ketrampilan dalam pelayanan kesehatan gigi khususnya dalam pembinaan UKGS

b. Kepada perawat gigi untuk lebih meningkatkan rasa keprihatinan terhadap pelaksanaan tugas pokok yang belum optimal, khusunya dalam hal cakupan kegiatan UKGS dengan lebih meningkatkan cakupan UKGS dan lebih meningkatkan frekuensi pembinaan.

\section{DAFTAR PUSTAKA}

Depkes RI. Pedoman Pelayanan Asuhan Kesehatan Gigi dan Mulut. Dirjend Yan. Medik. Jakarta. 2000. 
Depkes RI. Standar Pelayanan Puskesmas. Dir Jend Yan Medik. Jakarta, 2009.

Depkes RI. Pedoman UKGS Inovatif. Dirjend Yan. Medik. Jakarta. 2012

Dinas Kesehatan Kabupaten Semarang. Laporan Tahun 2009. Semarang, 2009

Menkes RI. Mewujudkan Kemandirian Kesehatan Masyarakat Berbasis Preventif Promotif. Seminar Nasional tanggal 13 Maret 2010 FKM Undip. Semarang. 2010.

Muninjaya, A.A.G. Manajemen Kesehatan. EGC. Jakarta. 2004 